\title{
Measuring Knowledge Management Capability Condition on the Support of Marine and Fishery Resources Utilisation
}

\author{
Roberto M. K. Teniwut, Cawalinya L. Hasyim, Wellem A. \\ Teniwut
}

Fishereis Agribusiness Study Program, Tual State Fisheries Polytechnic, Indonesia

\begin{abstract}
Economically and ecologically, marine environment plays an important role in all aspects of our life. Throughout human existence, we have relied on the marine environment for food, recreational activities, economic opportunities, and so on. For that reason, it is vital to protect, sustain, and improve the coastal zone as an aquatic resources and a habitat for wildlife. Managing coastal zones require involvements from many different stakeholders; however, the integration of all knowledge types -including local expertise and scientific knowledge -- with the policymaking is not without challenges. This paper looks at the resource based capability and knowledgebased capability perspectives in measuring the effectiveness of knowledge management in a rural coastal region, Southeast Maluku district. This research uses stepwise regression analysis method with 253 respondents. The results of this study indicate that resources based and knowledge based capabilities in this region are effective in supporting the application of knowledge capability management. However, the ability to obtain information and utilise information has not significantly impacted the development of knowledge capability management of fishery resources and marine in this region at the time of writing.
\end{abstract}

Paper type: Research paper

Keywords: Knowledge Management; Resources Based Capability; Knowledge Based Capability; Rural Coastal Regions, Southeast Maluku; Archipelago; Fishery 


\section{Introduction}

Knowledge management practice has received growing attention in the costal communities; for example, in the Northern Cape (Mabudafhasi, 2002), Timor and the Arafura Sea (Stacey et al., 2015), Solomon Islands (Folke et al. 2005), and Pacific regions (Harvey and Hilton, 2006). Studies have shown that knowledge management practices are often affected by the cultural and institutional contexts (Hussinki et al., 2017). However, limited work has been done in analysing the knowledge management initiatives in rural Indonesian coastal regions. Hence, this study aims to fill the research gap by examining the knowledge management practices in a rural Indonesian coastal region: the Southeast Maluku district.

The Maluku Islands are an archipelago within the Banda Sea, Indonesia. Unlike the northern and central parts of Maluku Islands which are covered by the rainforests, the Southeast Maluku province is sparsely vegetated and it has extensive coastal areas and inland swap (O'Connor et al., 2002). Given the remoteness and ecological environment of the Southeast Maluku province, the livelihoods on the Maluku province are largely depend on the surrounding marine environment, and marine-based activities constitute a significant proportion of economic activities and nutritional intakes in the province (O'Connor et al., 2002; Pannell, 1997; Steenbergen, 2016). However, the marine resources and ecosystems in Indonesia are not only threatened by the climate change but also over-exploitation, growing population, and pollution (Pannell, 1997). Given the significance of the marine environment to the rural coastal communities like the Southeast Maluku province, it is necessary to better utilise the scarce resources in a sustainable and efficient manner. This calls for a more thorough review of the current use of the marine environment, improve the current understanding of the coastal zone, and co-create a more sustainable way of undertaking marine-based activities.

The Southeast Maluku province is a rural coastal region and the interactions between economic and ecologic interests has resulted tensions in managing this coastal zone. These tensions have often emerged from sharing and integrating knowledge from different sources of information (e.g. researchers, local residents, policy makers, nongovernmental organisations). The objective of this paper is to analyse the knowledge management capability in Southeast Maluku Regency, with particular attention to the role of resource structuring and capability building in coastal communities.

\section{Literature Review}

\subsection{Knowledge Management in coastal regions}

The practice of sharing and managing of knowledge in coastal regions has attracted growing interests among the academics and policy makers. To promote sustainable practices in coastal regions, knowledge management plays a key role in coastal zone management (Puente-Rodríguez et al., 2015). Knowledge management may be instrumental in coastal regions, not only in terms of building knowledge capacities of the coastal communities, but also in situating them within wider development planning. The local residents can be mobilised to raise their concerns in relation to regional development or livelihood practices that are associated with ecological and

International Journal of Management and Applied Research, 2017, Vol. 4, No. 4 
economic interests. Furthermore, the local residents can contribute to the knowledge building and sharing in regard to local ecological knowledge (Berkes et al., 2007; Green and Raygorodetsky, 2010; Puente-Rodríguez et al., 2015).

However, the process of producing and sharing knowledge in the coastal regions is more complex than in contemporary corporations. The complexity of governance system is one of the reasons coastal knowledge could not be easily integrated into environmental and development policy (Acheson, 2006; Nursey-Bray et al. 2014; Shanley and Lopez, 2009). Researchers refer the barriers to implementing changes due to cultural and political interests as "knowledge-governance gap" (Cash et al. 2006). Compiling relevant traditional knowledge is proven to be a complicated task (Berkes et al., 2007) and transferring scientific knowledge to the local coastal communities is equally challenging (Cash et al. 2006). Additionally, the ongoing pervasive environmental changes (Harvey and Hilton, 2006) and globalisation constitute to challenge to managing knowledge in the coastal communities. The next section discusses the practice of knowledge management, with a focus on disseminating knowledge in the coastal communities.

\subsection{The practice of knowledge management}

In 2012, the World Bank Institute published a results-focused planning guide for development practitioners, titled The Art of Knowledge Exchange. The planning guide consists of five steps to develop and implement knowledge exchange: anchor it, define it, design and develop it, implement it, and lastly, report the results (Kumar and Leonard, 2012). The first step -- anchor it -- is about identifying development goal and institutional challenges as well as capacity development objectives. By setting specific goals and objectives, the knowledge management initiative would be more focused on the specific problems or issues which have triggered the initiation of the knowledge exchange and management (Puente-Rodríguez et al., 2015). The second step -- define it -- involves identification of the most appropriate knowledge providers and ideal participants profiles. The list of knowledge exchange participants may include a wide range of stakeholders, namely scientists, local residents, policy makers, nongovernmental organisations, etc. Identifying the most suitable partners is essential to successful knowledge management (Kumar and Leonard, 2012; Puente-Rodríguez et al., 2015). And for that reason, it is equally important to consider who should be excluded (Puente-Rodríguez et al., 2015). The following step -- design and develop -revolves around determining capacity objective and expected outcomes, assembling elements of exchange, and setting measurement goals. Since knowledge is socially developed and shared, structures that support mutual exchange of information is an enabler to knowledge management practices (Hussinki et al., 2017; Kumar and Leonard, 2012; Mabudafhasi, 2002). The next step -- implementation -- is concerned with project management and/or fine-tuning of the knowledge management practices and agenda. There are many forms and approaches to managing knowledge in coastal regions, and each approach presents an interesting dilemma to knowledge management participants (Puente-Rodríguez et al., 2015). Consequently, the knowledge management participants often fine tune their strategies and processes to facilitate efficient exchange of information. The last step -- report the results --focuses on documentation and detailed descriptions of the knowledge management initiative.

International Journal of Management and Applied Research, 2017, Vol. 4, No. 4 
To a great extent, these five steps mirror the four fundamental questions as identified by Puente-Rodríguez et al. (2015): why, who, what, and how. First, the why-question focuses on the reasons, issues, or problems that initiate the knowledge exchange at first place. Second, the who-question identifies the key actors and decision makers in the knowledge management initiative. Third, the what-question is concerned with what knowledge to be shared and assimilated. And lastly, the how-question is about creating and developing strategies to exchange and manage knowledge efficiently.

A closer examination on the work of Puente-Rodríguez et al. (2015) and Kumar and Leonard (2012) suggests that their views of knowledge management practices focus on the following issues: people, process, purpose, and content. This paper further develops the theoretical groundings by expanding $\mathrm{KM}$ practices into a six categorisations, which is based on the central premise of resource-based view: capability building and resource structuring (Barney et al., 2001). These six factors are: Culture Knowledge (CK), Technology (T), Organizational Structure (OS), Expertise Capability (EC), Learning Capability (LC), and Information Capability (IC). While the first three variables are based on resource-based perspective, the latter three are concerned with the knowledge-based perspective (Aujirapongpan et al., 2010). The next sections explain the six variables proposed to cover the most important aspects of $\mathrm{KM}$ in coastal regions.

\subsubsection{Culture Knowledge (CK)}

Knowledge represents a cumulative body of beliefs (Berkes et al., 2007), intellectual development (Hussinki et al., 2017), and cultural evolution (Green and Raygorodetsky, 2010). Knowledge can exists in various forms, including formal, informal, tacit, explicit, local, scientific, etc. Puente-Rodríguez et al. (2015) concluded that scientific knowledge alone is insufficient to create and maintain sustainable coastal communities, and the involvement of different stakeholders is required in order to cocreate knowledge in coastal regions. In particular, the involvement of local populations and local know-how are valued by the scientific communities in order to understand the local environmental conditions and habitats (Berkes et al., 2007; Green and Raygorodetsky, 2010; Puente-Rodríguez et al., 2015). Scholars refer the cultural and historical continuity of region-specific knowledge as "indigenous knowledge" (Green and Raygorodetsky, 2010), "community knowledge" (Nursey-Bray et al. 2014), "local knowledge" (Naess, 2012), and "traditional knowledge" (Berkes et al., 2007). In this study, we refer this type of knowledge as culture knowledge.

\subsubsection{Technology (T)}

Technology is often cited as an enabler to successful knowledge exchange and management (Hussinki et al., 2017; Kumar and Leonard, 2012; Mabudafhasi, 2002). Studies have shown that organisations built effective knowledge management system achieve by adopting a variety of organisational infrastructures and technological supports for storage, collaboration, real-time data, simulation, and search engine indexing (Aujirapongpan et al., 2010; Freeze and Kulkarni, 2007; Hussinki et al., 2017). Additionally, technological advancement such as big data analytics enables organisations to combine and utilise information from different sources of data and convert them into explicit knowledge (Sumbal et al., 2017). Puente-Rodríguez et al.

International Journal of Management and Applied Research, 2017, Vol. 4, No. 4 
(2015) reported that technological supports such as communication platforms and decision support tools are needed in the coastal management context. In short, technology can help to build a capacity for knowledge management.

\subsubsection{Organisational Structure (OS)}

Knowledge sharing and management is often affected by the organisational design issues, especially in terms of power distance and communication relationship (Aujirapongpan et al., 2010; Hussinki et al., 2017; Puente-Rodríguez et al., 2015). Organisational structure determines how information flows between and among levels of management; it also affects the extent to which functional roles and responsibilities are delegated and coordinated in disseminating information. For instance, a hierarchical organisational structure may be less efficient in disseminating information compared to cross-functional teams (Hussinki et al., 2017). Empirical studies have shown that supports from senior management, employee empowerment, and power decentralisation are positively correlated to the successful implementation of knowledge management systems (Hussinki et al., 2017; Yang and chen, 2007). Organisational structure is also relevant to knowledge management in coastal communities. While top-down regulatory framework appears necessary to enforce holistic coastal management and knowledge governance strategies, a bottom-up approach tends to emerge spontaneously in sharing knowledge related to coastal zone management (Puente-Rodríguez et al., 2015). In other words, organisational structure, or power distance and communication flow more specifically, is likely to affect the mechanism of knowledge sharing and management in the communities.

\subsubsection{Expertise Capability (EC)}

Aujirapongpan et al. (2010: 187) define Expertise Capability as the "capability of undertaking anything in a favourable way as a result of having a special kind of knowledge which comes from experience, practice and co-operation". In a similar way, Freeze and Kulkarni (2007: 97) describe the characteristics of Expertise knowledge as highly "tacit/implicit, domain-specific, originating through experience, formal education and collaboration". In other words, an in-depth understanding of a specialised discipline is a proficiency that distinguishes experts from novices. Potential indicators of Expertise Capability include capability to transfer knowledge as well as the ability to build knowledge network (Aujirapongpan et al., 2010). Coastal knowledge comprises of many different sources of expertises, ranging from scientists to local residents. For example, in the case of farmer engagement in the Taw Catchment, the farmers and land managers in the UK are "constituted as expert observers of ground-level processes and provide diverse information on farming practices, enterprise economics and underpinning attitudes towards risk" (Oliver et al., 2012: 76). The scientists, on the other hand, have focused on marine ecosystems and coastal problems such as sea-level rise, land erosion, biodiversity, and environmental issues. The successful integration of scientific knowledge and local ecological knowledge not only benefit the local coastal community but also the science communities at large. Local-level expert knowledge such as farming practices and land use can help to inform the Decision Support Systems (Oliver et al., 2012); similarly, local insights like fish location and species can be mapped by a Geographic Information System (Nursey-Bray et al., 2014).

International Journal of Management and Applied Research, 2017, Vol. 4, No. 4 


\subsubsection{Learning Capability (LC)}

Learning Capability refers to the capability to learn and the knowledge gained while working under various circumstances (Aujirapongpan et al., 2010; Freeze and Kulkarni, 2007). Such learning may take place at many different forms and levels. The capacity to embrace multiple forms of knowledge, in addition to the provision of a diversity of governance regimes, will create a good 'fit' over the geographies and scales of coastal regions (Nursey-Bray et al., 2014). Ability to Potential indicators of Learning Capability includes the capability to articulate (Oliver et al., 2012), ability to capture and transfer lessons learned (Freeze and Kulkarni, 2007), and motivated to study and co-create knowledge (Aujirapongpan et al., 2010).

\subsubsection{Information Capability (IC)}

The last variable from the knowledge-based capability perspective is the Information Capability, which refers to the "the capability to have valuable and beneficial information, both quantitatively and qualitatively" (Aujirapongpan et al., 2010: 188). In the context of coastal management, information includes specific location data and expert data, which often accumulated from many different sources. Potential indicators regarding information capability include the accessibility and the retrieval of data (Aujirapongpan et al., 2010), storage capacity (Nursey-Bray et al., 2014), and efficiency (Oliver et al., 2012).

\section{Methodology}

This study aims to identify and analyse the factors that affect the strategic acceleration and equitable knowledge capabilities of coastal communities in the management of marine resources and sustainable fisheries in Southeast Maluku Regency. A causal modelling approach was used in this research for our empirical investigation. The design of data analysis in this study in the first year is stepwise regression analysis to analyse the factors that influence gradually based on the conceptual groups that affect the acceleration and equity of knowledge capabilities of coastal communities in Southeast Maluku district. We used forward stepwise regression procedure as our main research analysis tools to process data obtained with the addition of Pearson correlation to view the relation between predicted and predictor variables. This method is used in order to choose predictive variable automatically from regression computation, whereas regression method in general, there should be classical assumption tests conducted prior forward stepwise regression procedure, consists of multicollinearity, autocorrelation and heteroscedasticity tests. Validity and reliability tests were conducted to measure the questionnaire used in this research (Figure 1).

International Journal of Management and Applied Research, 2017, Vol. 4, No. 4 
Figure 1: Steps of analysis method

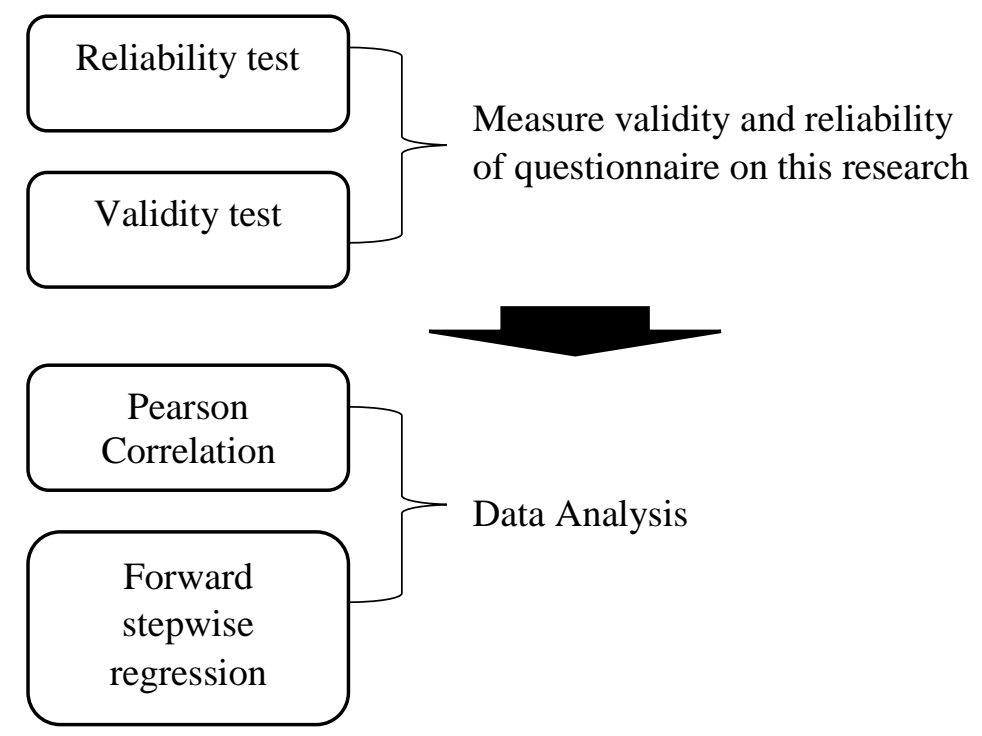

\subsection{Data Collection}

This study is based on both interviews and questionnaires, and the data were collected using the probability sampling method with a simple random sampling approach. The respondents of this research is a coastal community which is engaged in the management and utilisation of marine and fishery resources as the main source of economy in Southeast Maluku Regency, which include culture farmer, fishermen, fishery product seller and capital owner. The sample selection was conducted by conducting an initial survey to determine the location (Village) that became the target. The location of the research was conducted in 12 locations spread in Pulai Kei Kecil and Kei Besar, among others, Ohoidertutu Village, Ngilngof Village, Matwaer Village, River Village, Ngafan Village, Evu Village, Letvuan Village, Selayar Village, Dudunwahan Village, Sathean Village, and Ohoiren Village.

\subsection{Data Analysis}

The best model can be obtained from the variables studied using Forward Stepwise Regression Procedure. The forward elimination procedure is one of the best model selection procedures in regression with the elimination of independent variables that build the model gradually.

The steps are as follows:

1. Create a simple regression model for each independent variable. Then, each model is tested by a slope test with $F$. We compare the highest $F$ values, e.g., $F_{L}$, with certain fixed $F$ values from the table, for example, $F_{0}$. If $F_{L}<F_{0}$, means there's no independent variable that being choose

2. If $\mathrm{F}_{\mathrm{L}}>\mathrm{F}_{0}$, enter independent variable $\mathrm{L}$ to model.

International Journal of Management and Applied Research, 2017, Vol. 4, No. 4 
3. If at stage 1 there is an independent variable that is inserted (e.g., L), then we create a regression model with two independent variables in which one of them is variable $\mathrm{L}$, suppose free variable $\mathrm{L}$ and $\mathrm{K}$. Then we do partial $\mathrm{F}$ test: $\mathrm{F}_{\mathrm{K}}$ $=\frac{\operatorname{MSR}(K \mid L)}{\operatorname{MSE}(K, L)}$ then we make comparison model for higher $\mathrm{F}$ value, where $\mathrm{F}_{\mathrm{K}}$ with certain $\mathrm{F}$ value, then $\mathrm{F}_{0}$.

a) If $\mathrm{F}_{\mathrm{K}}<\mathrm{F}_{0}$, means that only 1 independent variable in the model.

b) If $\mathrm{F}_{\mathrm{K}}>\mathrm{F}_{0}$, means that we can enter variable $\mathrm{K}$ in the model.

4. If on second step there is independent variable available $(\mathrm{K})$, then stepwise will check whether the independent variable in model been dropped out or not.

$$
\text { Partial F test: } \mathrm{F}_{\mathrm{L}}=\frac{M S R(L \mid K)}{\operatorname{MSE}(L, K)} \text {. }
$$

a) If $F_{L}<F_{0}$, means that independent variable $L$ expelled from the model.

b) If $\mathrm{F}_{\mathrm{K}}>\mathrm{F}_{0}$, means that independent variable $\mathrm{L}$ and $\mathrm{K}$ include in the model.

Suppose we keep the independent variable L. Thus, the independent variables $\mathrm{L}$ and $\mathrm{K}$ are used in the model. Furthermore, the stages repeated until no more variables are added or removed. Using SPSS 24, the regression model used as follows:

$$
\begin{aligned}
& K C M=a_{0}+\beta_{1} T+\beta_{2} O S+\beta_{3} O C+\beta_{4} L C+\beta_{5} I C+\beta_{6} E C+\varepsilon \\
& \text { Where: } \\
& \mathrm{KCM}=\text { Knowledge Capability Management } \\
& \mathrm{T} \quad=\text { Technology } \\
& \mathrm{OS}=\text { Organizational Structure } \\
& \mathrm{OC}=\text { Organizational Culture } \\
& \text { LC = Learning Capability } \\
& \text { IC } \quad=\text { Information Capability } \\
& \mathrm{EC} \quad=\text { Expertise Capability } \\
& \varepsilon \quad=\text { Error }
\end{aligned}
$$

This study initially set a target respondents were 280 , then after the distribution of questionnaires, only 278 pieces of questionnaires were returned and only as many as 253 questionnaires that meet the statistical requirement to be included in the calculation of this research. Before proceeding to the stage of data processing, it is necessary to test the instrument, in this case, is a test of reliability and validity.

\subsection{Validity test}

Validity test is a test to measure the level of validity of an instrument. An instrument is said to be valid if it can measure what is desired or can reveal data from the variables studied appropriately. Validity test is done by finding a correlation of each indicator to its total score by using correlation technique The Pearson Product Moment. The results

International Journal of Management and Applied Research, 2017, Vol. 4, No. 4 
of testing question instruments in the questionnaire used in this study can be seen in table 1 below:

Table 1: Validity result

\begin{tabular}{|c|c|c|c|c|}
\hline Variable & $\begin{array}{l}\text { Questions } \\
\text { items }\end{array}$ & $\begin{array}{l}\text { Coefficient } \\
\text { correlation }\end{array}$ & $p$-value & Decision \\
\hline \multirow[t]{4}{*}{ Culture Knowledge (CK) } & CK1 & 0.865 & $0.000^{* *}$ & \multirow{4}{*}{ Valid } \\
\hline & CK2 & 0.919 & $0.000^{* *}$ & \\
\hline & CK3 & 0.909 & $0.000^{* *}$ & \\
\hline & CK4 & 0.871 & $0.000^{* *}$ & \\
\hline \multirow[t]{5}{*}{ Technology $(\mathrm{T})$} & $\mathrm{T} 1$ & 0.836 & $0.000^{* *}$ & \multirow{5}{*}{ Valid } \\
\hline & $\mathrm{T} 2$ & 0.872 & $0.000^{* *}$ & \\
\hline & T3 & 0.882 & $0.000^{* *}$ & \\
\hline & $\mathrm{T} 4$ & 0.868 & $0.000^{* *}$ & \\
\hline & T5 & 0.817 & $0.000^{* *}$ & \\
\hline \multirow[t]{4}{*}{ Organizational Structure (OS) } & OS1 & 0.868 & $0.000^{* *}$ & \multirow{4}{*}{ Valid } \\
\hline & OS2 & 0.903 & $0.000^{* *}$ & \\
\hline & OS3 & 0.906 & $0.000^{* *}$ & \\
\hline & OS4 & 0.829 & $0.000^{* *}$ & \\
\hline \multirow[t]{4}{*}{ Expertise Capability (EC) } & EC1 & 0.859 & $0.000^{* *}$ & \multirow{4}{*}{ Valid } \\
\hline & $\mathrm{EC} 2$ & 0.869 & $0.000^{* *}$ & \\
\hline & EC3 & 0.891 & $0.000^{* *}$ & \\
\hline & EC4 & 0.832 & $0.000^{* *}$ & \\
\hline \multirow[t]{3}{*}{ Learning Capability (LC) } & LC1 & 0.899 & $0.000^{* *}$ & \multirow{3}{*}{ Valid } \\
\hline & $\mathrm{LC} 2$ & 0.893 & $0.000^{* *}$ & \\
\hline & LC3 & 0.911 & $0.000^{* *}$ & \\
\hline \multirow[t]{3}{*}{ Information Capability (IC) } & IC1 & 0.889 & $0.000^{* *}$ & \multirow{3}{*}{ Valid } \\
\hline & IC2 & 0.924 & $0.000^{* *}$ & \\
\hline & IC3 & 0.899 & $0.000^{* *}$ & \\
\hline
\end{tabular}

$* *$ significant $\mathrm{N}=253$

The results of testing the validity of the items of the questions used in this study indicate that all items signify valid questions in the sense that the items of questions represent variables adequately measured in the study, further followed by reliability testing to analyze the consistency of the variables in this study.

\subsection{Reliability test}

Reliability is a measure that indicates the stability and consistency of an instrument that measures a concept and is useful for accessing the feasibility of measurement (Sekaran, 2000). Reliability test is performed by using Alpha Cronbach to measure the internal consistency between the variables in the instrument, whether or not the instruments used in this study are feasible and related, with a reliability coefficient value greater than 0.5 to near 1 , indicating that the variables are consistent. 
Table 2: Reliability result

\begin{tabular}{llll}
\hline No & Variable & Coefficient reliability & Decision \\
\hline 1 & Culture Knowledge (CK) & 0.914 & Reliable \\
2 & Technology (T) & 0.908 & Reliable \\
3 & Organizational Structure (OS) & 0.899 & Reliable \\
4 & Expertise Capability (EC) & 0.884 & Reliable \\
5 & Learning Capability (LC) & 0.884 & Reliable \\
6 & Information Capability (IC) & 0.888 & Reliable \\
\hline
\end{tabular}

In Table 2 above can be seen that, the results of reliability tests on the variables used in the study showed that all variables in this study meet the criteria of reliability, which means that the variables in this study consistent.

\section{Results}

This study uses two analytical tools in accordance with the objectives to be achieved, where the first was the Pearson correlation test to test the interrelations between independent variables and dependent variable with the aim to test the relationship between variables and the second was stepwise regression for analyzing the effect of resources based capability (RBC) that is culture knowledge, technology, organizational structure and knowledge-based capability $(\mathrm{KBC})$ that is expertise capability, learning capability, information capability on knowledge capability.

\subsection{Pearson Correlation Test}

The results of correlation test between independent variables with a dependent variable can be seen in table 3 below:

Table 3: Correlation test

\begin{tabular}{lccl}
\hline Variable & $\begin{array}{c}\text { Coefficient } \\
\text { correlation }\end{array}$ & p-value & Decision \\
\hline Culture Knowledge (CK) & 0.748 & $0.000^{* *}$ & Significant relationship \\
Technology (T) & 0.821 & $0.000^{* *}$ & Significant relationship \\
Organizational Structure (OS) & 0.778 & $0.000^{* *}$ & Significant relationship \\
Expertise Capability (EC) & 0.794 & $0.003^{* *}$ & Significant relationship \\
Learning Capability (LC) & 0.744 & $0.000^{* *}$ & Significant relationship \\
Information Capability (IC) & 0.569 & $0.000^{* *}$ & Significant relationship \\
\hline
\end{tabular}

$* *$ significant at $\alpha=1 \%$

The correlation test (to determine whether the independent variables related to the dependent variable in Table 3) shows that, six independent variables have a significant relationship with knowledge capability in Southeast Maluku Regency. These results indicate that both resource-based capability and knowledge-based capability are linked to the development of knowledge of coastal communities in the region. The results indicate that there is a need for a comprehensive emphasis on all related variables to obtain equity and acceleration of knowledge management of fisheries resources by sustainable coastal communities.

International Journal of Management and Applied Research, 2017, Vol. 4, No. 4 


\subsection{Stepwise Regression Analysis}

This analytical tool is used to determine the influence of each group of variables separately and simultaneously to the dependent variable. It aims to obtain a detailed and gradual description of the effect of each resource based capability and knowledgebased capability on the equitable distribution and knowledge management of fishery resources by sustainable coastal communities in a single regression test. The results of the analysis of stepwise regression analysis in this study can be seen in Table 4 below:

Table 4: Stepwise Regression Analysis

\begin{tabular}{|c|c|c|c|}
\hline First step & Second step & $\begin{array}{l}\text { Coefficient } \\
\text { regression }\end{array}$ & $p$-value \\
\hline Culture Knowledge (CK) & & 0.086 & $0.058^{*}$ \\
\hline Technology $(T)$ & & 0.398 & $0.000^{* *}$ \\
\hline \multirow[t]{7}{*}{ Organizational Structure (OS) } & & 0.487 & $0.000^{* *}$ \\
\hline & Culture Knowledge (CK) & 0.076 & $0.059^{*}$ \\
\hline & Technology $(T)$ & 0.318 & $0.000 * *$ \\
\hline & Organizational Structure (OS) & 0.267 & $0.000 * *$ \\
\hline & Expertise Capability $(E C)$ & 0.161 & $0.001 * *$ \\
\hline & Learning Capability $(L C)$ & 0.389 & $0.000 * *$ \\
\hline & Information Capability (IC) & -0.015 & 0.740 \\
\hline $\mathrm{R}^{2}=81.3 \%$ & $\mathrm{R}^{2}=86.2 \%$ & & \\
\hline $\mathrm{F}$ value $=358.434\left(0.000^{* *}\right)$ & $\begin{array}{c}\text { F value }=254.142(0.000 * *) \\
\text { Durbin Watson }=1.833 \\
\text { VIF }<4\end{array}$ & & \\
\hline
\end{tabular}

$* *$ significant in $\alpha=0.05(95 \%)$; *significant in $\alpha=0.1(90 \%)$

From the results of stepwise regression analysis (Table 4) it can be seen that DW value is equal to 1.833, indicated that from six independent variables within 253 sample, that the $\mathrm{dL}$ and $\mathrm{dU}$ are sequentially 1.7071 and 1.8306 , so 4-dL and 4-dU were respectively 2.2929 and 2.1694 which means that it passed the autocorrelation test because the value of $\mathrm{DW}$ is between the $\mathrm{dU}$ and 4-dU is 2.197. Then the multicollinearity test shows that all VIF values are $<10$ so it is concluded that this regression equation passed the multicollinearity test, then the heteroscedasticity test can be seen on scatter plot test result (see Figure 2).

International Journal of Management and Applied Research, 2017, Vol. 4, No. 4 
Figure 2: Scatter Plot regression for heteroscedasticity

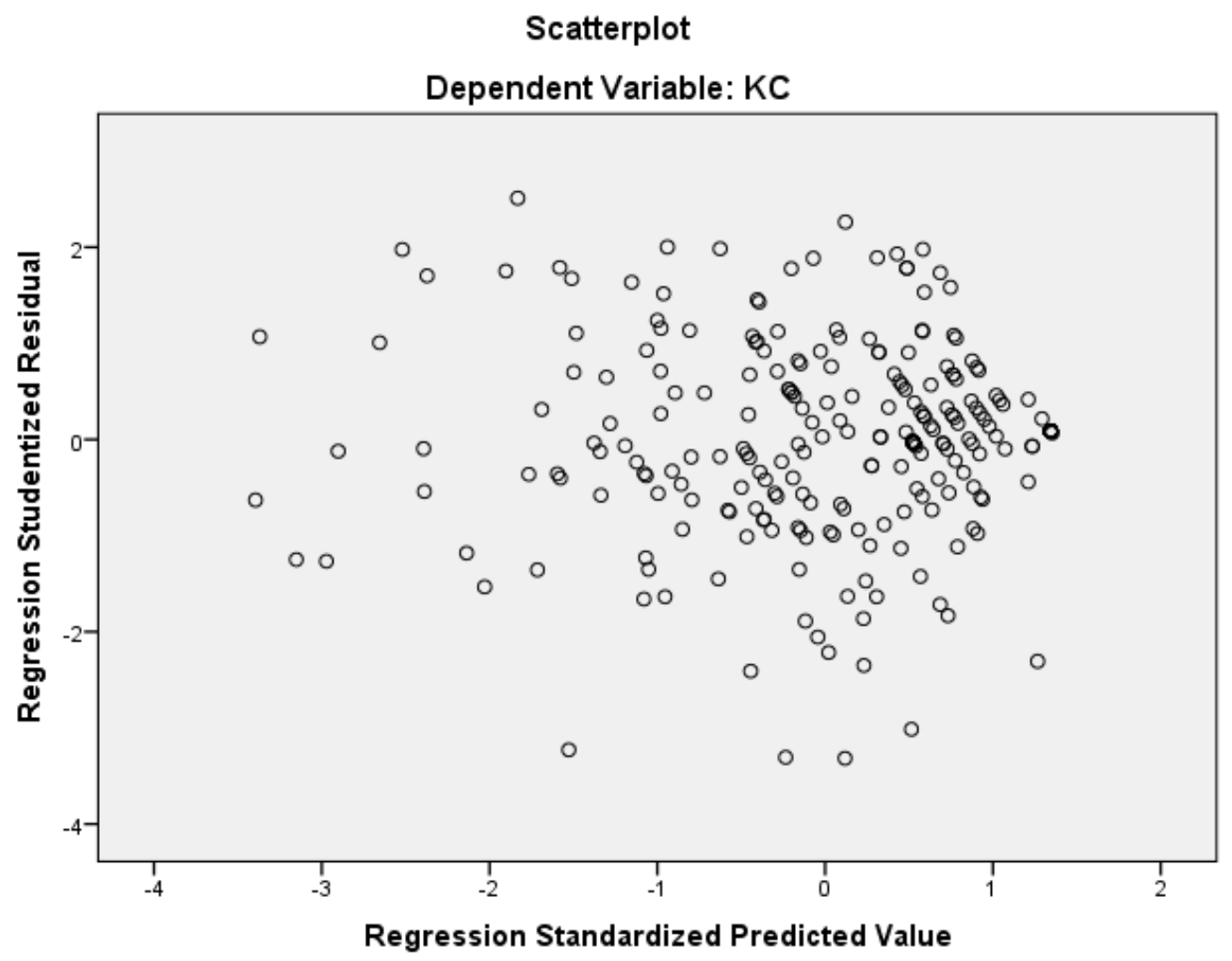

The final result of stepwise regression analysis in this study passed the test of classic assumption; hence, it's worth continuing to significance testing. In the above results, it can be seen that the value of $\mathrm{R}^{2}$ in the first stage where the variable resources-based capability is only regressed the dependent variable has a value of $81.3 \%$ and increase to $86.2 \%$ when the variables that represent the knowledge-based capability are also included in the regression equation. These results indicated that the second stage provides the measurement results which are closer to reality than the first stage of regression results. So it was decided that the second stage are to be used for the discussion of regression. From the above results can also be seen that the model is a good fit with a significance level of $0.000<0.050$, thus concluding that the regression equation in this study fits for use in discussion.

International Journal of Management and Applied Research, 2017, Vol. 4, No. 4 
Figure 3: Regression Results

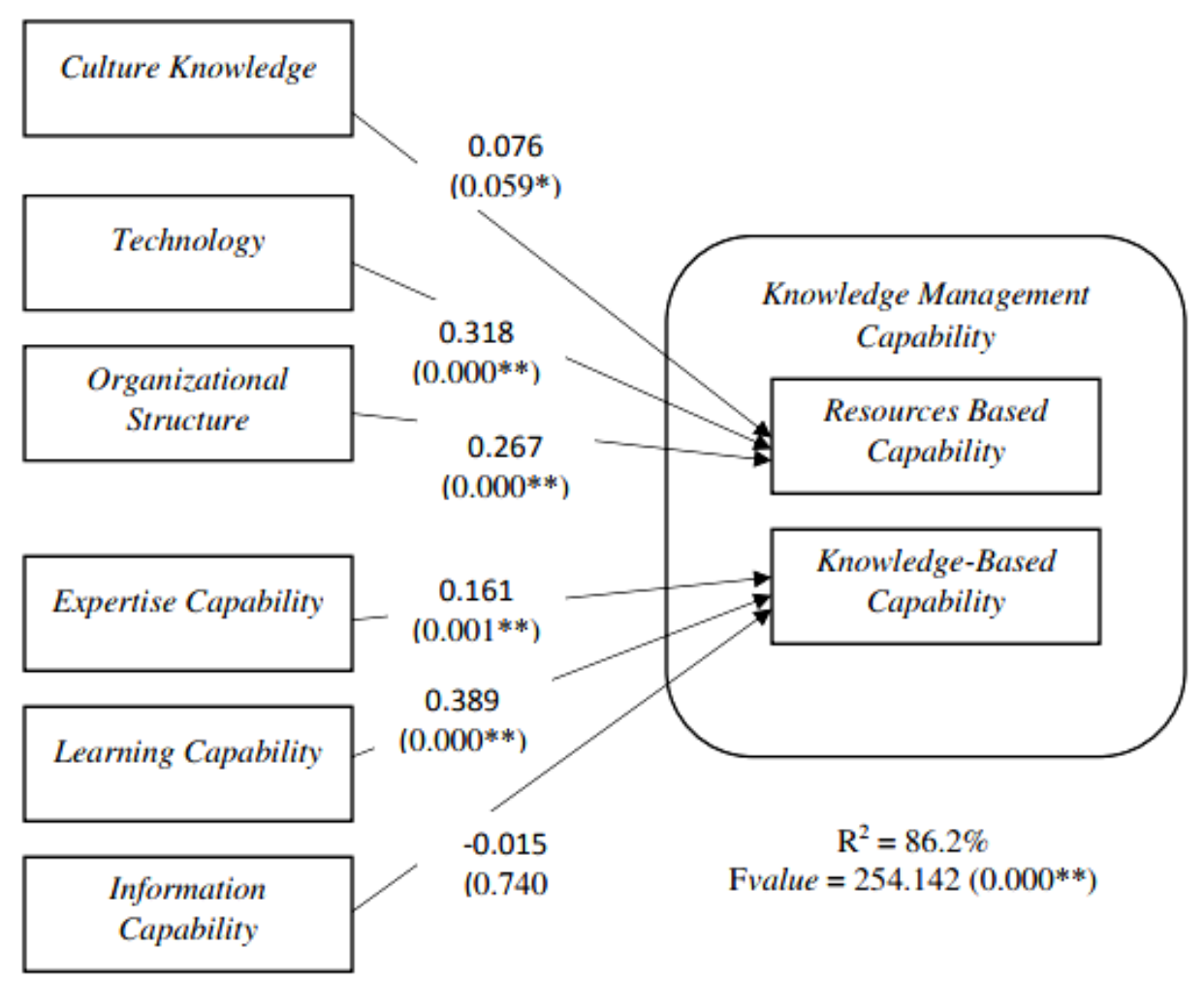

\section{Discussion}

The six factors representing a knowledge-based capability and resource-based capability have a strong relationship with knowledge management capability in the region. However, based on the results of research, the Information Capability -- which is one of the variables of the knowledge-based capabilities -- has no significant influence in this region. This condition becomes a huge concern for local government because the party that acts as management in Southeast Maluku district, organises information flow, form and accuracy of information, information delivery and evaluation of coastal resource management information is not well-managed.

Based on the results, resource based perspective (Culture Knowledge, Technology, and Organisational Structure) has a positive impact on knowledge management capability in this region. More specifically, the organisational structure and custom belief of coastal community in the Southeast Maluku district form a solid basis for knowledge management capability. Aside of regional office in district capital, there are county offices in the middle of each coastal county, which makes its easier to get access to information and latest knowledge. In addition, there is local wisdom in Kei Islands community named "Ain ni Ain" which means everyone in the region is family. Chuang (2004) pointed out that such conducive condition will increase knowledge coordinating, co-operating and knowledge acquiring. This result also points out that

International Journal of Management and Applied Research, 2017, Vol. 4, No. 4 
organizational structure in the area had a positive effect on KM capability in the region. This indicates that formal and informal government and community structure in the region do fit with the KM effectiveness criteria, where the coastal community can easily contact the government office and researcher in the area directly. Additionally, the technology factor also supports KM capability in the Southeast Maluku district as accessibility to the technology is quite high. This finding supports the study of Yang and Chen (2007) which concluded that structural, technical, and human knowledge capability are significant to the KM capability.

Furthermore, the results of this study also showed that knowledge based capability (expertise capability and learning capability) of the coastal community in the Southeast Maluku district supports the KM capability. Expertise capability in this context is related to tacit knowledge, which is based on the accumulated expertise from the elders, experience, and practice,(Naess, 2012). On top of that, learning knowledge also has a positive impact on KM capability in the region. Capability of coastal community to learn is also supported by their willingness to improve their capability, although we have found that coastal community in the region tends to be more sceptical about new knowledge their provided with, but we also found that person who provides the knowledge also has impact on the capacity of coastal community to receive and assimilate knowledge. For information capability, the results show that it has no significant impact on KM capability in the region. Information capability related to the capability to utilize the information they get, in which based on our findings some of the information provided to the coastal community does not fit with the real conditions. The rate of education background also contributes to this situation.

\section{Research Implications}

In general, the results indicate that the resources-based and knowledge-based perspectives have a positive impact on KM capability in the region, although information capability is deficient. Therefore it is necessary to conduct training and periodic assistance to increase coastal community capability to use the obtained information sufficiently. Training, material and assistance can be provided by the research institution in collaboration with local and central government. This region has the better core for KM capability; though, there is need for the further study on the real impact of knowledge sharing between coastal community and government along with NGOs on the utilisation of the marine and coastal resources in the region.

\section{Acknowledgements}

The authors would like to thank the research and community service directorate of Ministry of Research Technology and Higher Education, Republic of Indonesia to fund this research under PPT Research Scheme, 2017. 


\section{References}

1. Acheson, J. M. (2006), "Institutional failure in resource management", Annual Review of Anthropology, Vol. 35, No. 1, pp. 117-134.

https://doi.org/10.1146/annurev.anthro.35.081705.123238

2. Aujirapongpan, S.; Vadhanasindhu, P.; Chandrachai, A. and Cooparat, P. (2010) "Indicators of knowledge management capability for KM effectiveness", VINE, Vol. 40, No. 2, pp.183-203, https://doi.org/10.1108/03055721011050677

3. Barney, J.; Wright, M. and Ketchen, D. (2001), "The resource-based view of the firm: Ten years after 1991", Journal of Management, Vol. 27, No. 6, pp. 625 641. https://doi.org/10.1177/014920630102700601

4. Berkes, F.; Berkes, M. K. and Fast, H. (2007), "Collaborative Integrated Management in Canada's North: The Role of Local and Traditional Knowledge and Community-Based Monitoring", Coastal Management, Vol. 35, No. 1, pp. 143162. https://doi.org/10.1080/08920750600970487

5. Chuang, S.H. (2004), “A resource-based perspective on knowledge management capability and competitive advantage: an empirical investigation", Expert Systems with Applications, Vol. 27, No. 3, pp. 459-65. https://doi.org/10.1016/j.eswa.2004.05.008

6. Freeze, R. D. and Kulkarni, U. (2007), "Knowledge management capability: defining knowledge assets", Journal of Knowledge Management, Vol. 11, No. 6, pp.94-109, https://doi.org/10.1108/13673270710832190

7. Folke, C., Hahn, T., Olsson, P., and Norberg, J., (2005), "Adaptive Governance of social-ecological systems", Annual Review of Environmental Resources, Vol. 30, No. 1, pp. 441-473. https://doi.org/10.1146/annurev.energy.30.050504.144511

8. Green, D. and Raygorodetsky, G. (2010), "Indigenous knowledge of a changing climate", Climatic Change, Vol. 100, No. 2, pp. 239-242. https://doi.org/10.1007/s10584-010-9804-y

9. Harvey, N. and Hilton, M., (2006), "Coastal management in the Asia-Pacific region", In: Harvey, N. (Ed.), Global Change and Integrated Coastal Management: The Asia-Pacific Region. Coastal Systems and Continental Margins, Volume 10, The Netherlands: Springer, pp. 39-66. https://doi.org/10.1007/1-4020$\underline{3628-0 \_3}$

10. Hussinki, H.; Kianto, A.; Vanhala, M. and Ritala, P. (2017), "Assessing the universality of knowledge management practices", Journal of Knowledge Management, Vol. 21, No. 6, pp.1596-1621, https://doi.org/10.1108/JKM-09$\underline{2016-0394}$

International Journal of Management and Applied Research, 2017, Vol. 4, No. 4 
11. Kumar, S., Leonard, A. (2012), The Art of Knowledge Exchange: a Results-focused Planning Guide for Development Practitioners. Washington DC: World Bank. Available from: https://openknowledge.worldbank.org/handle/10986/11983 (accessed on 17 Nov 2017).

12. Mabudafhasi, R. (2002), "The role of knowledge management and information sharing in capacity building for sustainable development - an example from South Africa", Ocean \& Coastal Management, Vol. 45, No. 9-10, pp. 695-707. https://doi.org/10.1016/S0964-5691(02)00094-7

13. Naess, O. (2012), "The role of local knowledge in adaptation to climate change", WIREs Climate Change, Vol. 4, No. 2, pp. 99-106. https://doi.org/10.1002/wcc.204

14. Nursey-Bray, M. J., Vince, J., Scott, M., Haward, M., O’Toole, K., Smith, T., Harvey, N. and Clarke, B. (2014), "Science into policy? Discourse, coastal management and knowledge", Environmental Science \& Policy, Vol. 38, pp. 107119. https://doi.org/10.1016/j.envsci.2013.10.010

15. O’Connor, S.; Aplin, K.P.; Spriggs, M.; Veth, P. and Ayliffe, L.K. (2002), "From savannah to rainforest: changing environments and human occupation at Liang Lemdubu, Aru Islands, Maluku (Indonesia)", in: P. Kershaw, B. David, N. Tapper, D. Penny, J. Brown (Eds), Bridging Wallace's Line: The Environmental and Cultural History and Dynamics of the SE-Asian-Australian Region, Volume 34 of Advances in Geoecology, Reiskirchen: Catena Verlag, pp. 279-306.

16. Oliver, D.M. Fish, R.D. Winter, M. Hodgson, C.J. Heathwaite, A.L. Chadwick, D.R. (2012), "Valuing local knowledge as a source of expert data: farmer engagement and the design of decision support systems", Environmental Modelling and Software, Vol. 36, pp. 76-85. https://doi.org/10.1016/j.envsoft.2011.09.013

17. Pannell, S. (1997), "Managing the Discourse of Resource Management: The Case of Sasi from Southeast Maluku, Indonesia", Oceania, Vol. 67, No. 4, pp. 289-307.

18. Puente-Rodríguez, D., Giebels, D. and de Jonge, V. N. (2015), "Strengthening coastal zone management in the Wadden Sea by applying knowledge-practice interfaces", Ocean \& Coastal Management, Vol. 108, pp. 27-38. https://doi.org/10.1016/j.ocecoaman.2014.05.017

19. Shanley, P. and Lopez, C. (2009), "Out of the loop: why research rarely reaches policy makers and the public and what can be done", Biotropica, Vol. 41, No. 5, pp. 535-544. https://doi.org/10.1111/j.1744-7429.2009.00561.X

20. Stacey, N., Karam, J., Jackson, M., Kennett, R., and Wagey, T. (2015), "Knowledge exchange as a tool for transboundary and coastal management of the Arafura and Timor Seas", Ocean \& Coastal Management, Vol. 114, pp. 151-163. https://doi.org/10.1016/j.ocecoaman.2015.06.007

International Journal of Management and Applied Research, 2017, Vol. 4, No. 4 
21. Steenbergen, D. (2016), "Strategic Customary Village Leadership in the Context of Marine Conservation and Development in Southeast Maluku, Indonesia", Human Ecology, Vol. 44, No. 3, pp.-327. https://doi.org/10.1007/s10745-016-9829-6.

22. Sumbal, M. S.; Eric Tsui, E. and See-To, E. W.K. (2017), "Interrelationship between big data and knowledge management: an exploratory study in the oil and gas sector", Journal of Knowledge Management, Vol. 21, No. 1, pp.180196. https://doi.org/10.1108/JKM-07-2016-0262

23. Yang, C. and Chen, L.-C. (2007), "Can organizational knowledge capabilities affect knowledge sharing behavior?", Journal of Information Science, Vol. 33 No. 1, pp. 95-109. https://doi.org/10.1177\%2F0165551506068135 